Article

\title{
Lipofuscin-Type Pigment as a Marker of Colorectal Cancer
}

\author{
Sónia Carvalho ${ }^{1}$, Isa Carneiro ${ }^{1}$, Rui Henrique ${ }^{1,2} \mathbb{D}$, Valery Tuchin ${ }^{3,4,5}$ and Luís Oliveira ${ }^{6,7, * \mathbb{C}}$ \\ 1 Department of Pathology and Cancer Biology, and Epigenetics Group-Research Center, Portuguese Oncology \\ Institute of Porto, 4200-072 Porto, Portugal; soniadiasdecarvalho@gmail.com (S.C.); \\ isa_carneiro@hotmail.com (I.C.); henrique@ipoporto.min-saude.pt (R.H.) \\ 2 Department of Pathology and Molecular Immunology, Institute of Biomedical Sciences Abel \\ Salazar-University of Porto (ICBAS-UP), 4050-313 Porto, Portugal \\ 3 Research-Educational Institute of Optics and Biophotonics, Saratov State University, Saratov 410012, Russia; \\ tuchinvv@mail.ru \\ 4 Interdisciplinary Laboratory of Biophotonics, National Research Tomsk State University, Tomsk 634050, Russia \\ 5 Laboratory of Laser Diagnostics of Technical and Living Systems, Institute of Precision Mechanics and \\ Control of the Russian Academy of Sciences, Saratov 410028, Russia \\ 6 Physics Department-Polytechnic Institute of Porto, School of Engineering, 4249-015 Porto, Portugal \\ 7 Centre of Innovation in Engineering and Industrial Technology (CIETI), School of Engineering, \\ Polytechnic of Porto, 4249-015 Porto, Portugal \\ * Correspondence: 1mo@isep.ipp.pt
}

Received: 12 October 2020; Accepted: 28 October 2020; Published: 31 October 2020

\begin{abstract}
The study of the optical properties of biological tissues for a wide spectral range is necessary for the development and planning of noninvasive optical methods to be used in clinical practice. In this study, we propose a new method to calculate almost all optical properties of tissues as a function of wavelength directly from spectral measurements. Using this method, and with the exception of the reduced scattering coefficient, which was obtained by traditional simulation methods, all the other optical properties were calculated in a simple and fast manner for human and pathological colorectal tissues. The obtained results are in good agreement with previous published data, both in magnitude and in wavelength dependence. Since this method is based on spectral measurements and not on discrete-wavelength experimental data, the calculated optical properties contain spectral signatures that correspond to major tissue chromophores such as DNA and hemoglobin. Analysis of the absorption bands of hemoglobin in the wavelength dependence of the absorption spectra of normal and pathological colorectal mucosa allowed to identify differentiated accumulation of a pigment in these tissues. The increased content of this pigment in the pathological mucosa may be used for the future development of noninvasive diagnostic methods for colorectal cancer detection.
\end{abstract}

Keywords: optical properties of tissues; tissue spectroscopy; differentiated pigment content; colorectal cancer; optical cancer detection; absorption coefficient; scattering coefficient; scattering anisotropy; light penetration depth

\section{Introduction}

Human colorectal cancer is a major concern worldwide, with high numbers of incidence per year, most of them resulting in fatality [1]. With the objective of developing new noninvasive optical methods to replace the ionizing radiation methods currently used to detect and treat diseases such as cancer, the research in the field of biophotonics has strongly increased in the last three decades [2]. To develop such alternative optical methods, knowledge on the optical properties of normal and pathological tissues is necessary for a wide wavelength range. Current optical diagnostic and therapeutic methods work at 
wavelengths within the traditional tissue windows: I (625-975 nm), II (1100-1350 nm), III (1600-1870 nm), and IV (2100-2300 nm) [3,4]. Complementary to these wavelength ranges, where light penetration depth presents local maxima for natural tissues $[2,5]$, the use of optical clearing treatments can induce other optical diagnostic and treatment windows, as it was recently demonstrated for the ultraviolet (UV) range with transmittance efficiency peaks at $(230 \pm 30),(275 \pm 25 \mathrm{~nm})$, and $(300 \pm 40 \mathrm{~nm})[6,7]$.

Considering the current optical methods that work at visible and near infrared (NIR) wavelengths, the above-indicated recent discovery of UV-windows to diagnose and treat pathologies and the emerging techniques at $\mathrm{THz}$ frequencies [8], it becomes urgent to map the optical properties of normal and pathological tissues for a wide spectral range. A set of optical properties can be considered as the identity card of any biological material, meaning that their evaluation can be used to discriminate between normal and pathological tissues. Their knowledge is also necessary to create individual light propagation models, which are necessary for the development of noninvasive optical diagnostic and treatment procedures [9-11]. Various studies were made to evaluate the wavelength dependencies for the various optical properties of different biological tissues $[5,9,12-19]$. Between the several optical properties that can be used to characterize a particular biological material, some of them, such as the absorption coefficient $\left(\mu_{\mathrm{a}}\right)$, the scattering coefficient $\left(\mu_{\mathrm{s}}\right)$, the scattering anisotropy factor $(g)$, and the refractive index (RI) are fundamental, but others that derive from these are also commonly used $[2,19]$. One of those derived properties is the reduced scattering coefficient $\left(\mu^{\prime}{ }_{s}\right)$, which can be calculated from $\mu_{\mathrm{s}}$ and $g[2,5,10]$ :

$$
\mu^{\prime}=\mu_{\mathrm{s}}(1-g) .
$$

Another very useful optical property is the light penetration depth, $\delta$, which quantifies how deep light can penetrate in a tissue. Considering the diffusion approximation, its calculation is made using $\mu_{\mathrm{a}}$ and $\mu_{\mathrm{s}}^{\prime}[2,13]$ :

$$
\delta=\frac{1}{\sqrt{3 \mu_{a}\left(\mu_{a}+\mu_{s}^{\prime}\right)}} .
$$

In general, for the UV range, both $\mu_{\mathrm{s}}$ and $\mu_{\mathrm{s}}^{\prime}$ have high values, leading to low values for $\delta$, but with the application of optical clearing treatments, such values can increase at some particular UV wavelengths, as indicated above. In opposition, for longer wavelengths, in the visible and near-infrared (NIR) range, scattering is low and $\delta$ reaches higher values $[19,20]$. Steven Jacques in his widely cited review paper (more than 2500 citations in Google Scholar) has summarized the wavelength dependencies of the optical properties of different biological tissues [20]. According to this paper, the absorption coefficient shows a decreasing behavior with increasing wavelength, since major chromophores, such as proteins, DNA and hemoglobin present their absorption bands in the UV and visible range $[6,20]$. In addition, due to the presence of water or lipids, some other absorption bands might occur in the NIR range. The wavelength dependence for $\mu_{\mathrm{a}}$, in a tissue, is the sum of the absorption contributions from all tissue components [20].

Considering the UV-NIR range, the scattering coefficients also show a decreasing behavior with increasing wavelength and such dependence is a combination of Rayleigh and Mie scattering regimes $[15,20]$ :

$$
\mu_{\mathrm{s}} \text { or } \mu_{\mathrm{s}}^{\prime}=a^{\prime}\left(f_{\text {Ray }}\left(\frac{\lambda}{500(\mathrm{~nm})}\right)^{-4}+\left(1-f_{\text {Ray }}\right)\left(\frac{\lambda}{500(\mathrm{~nm})}\right)^{-b_{\text {Mie }}}\right),
$$

where $a^{\prime}$ is a scaling factor that represents $\mu_{\mathrm{s}}$ or $\mu_{\mathrm{s}}^{\prime}$ at $500 \mathrm{~nm}, f_{\text {Ray }}$ is the Rayleigh scattering fraction, and $b_{\text {Mie }}$ characterizes the mean size of Mie scatterers. Such equation has been successfully applied to fit the wavelength dependence for data of many biological soft tissues [20-22].

Equation (3) describes a smooth wavelength dependence for both scattering coefficients in the spectral range from UV to NIR. As a result, and considering Equation (1), $g$ will have a smooth 
increasing behavior with increasing wavelength, which can be described by Equation (4) [5] or by Equation (5) [17]:

$$
\begin{gathered}
g(\lambda)=a+b\left[1-\exp \left(\frac{\lambda-c}{d}\right)\right], \\
g(\lambda)=a \cdot \exp (b \cdot \lambda)+c \cdot \exp (d \cdot \lambda) .
\end{gathered}
$$

The estimation of the parameters $a^{\prime}, f_{\text {Ray }}$ and $b_{\text {Mie }}$ in Equation (3) and $a, b, c$, and $d$ in Equations (4) or (5) is made when fitting the discrete $\mu_{\mathrm{s}}, \mu_{\mathrm{s}}^{\prime}$ and $g$ data, which are usually estimated along with $\mu_{\mathrm{a}}$ data, using inverse simulation codes based on the Adding-Doubling [23] or Monte Carlo [24] methods. To perform such inverse simulations, experimental data from the tissue, such as total transmittance $\left(T_{\mathrm{t}}\right)$, collimated transmittance $\left(T_{\mathrm{c}}\right)$ and total reflectance $\left(R_{\mathrm{t}}\right)$ are necessary. The RI data is also necessary to perform these simulations and it can be measured experimentally at discrete wavelengths through various methods [2]. Once the discrete RI values are obtained from measurements, the corresponding wavelength dependency (called dispersion) for a specific spectral range can be obtained by fitting the experimental values with an empirical relation, such as the Cauchy (Equation (6)), the Conrady (Equation (7)) [25-27], or the Cornu (Equation (8)) equations [2,18,19,28,29]:

$$
\begin{aligned}
& n(\lambda)=A+\frac{B}{\lambda^{2}}+\frac{C}{\lambda^{4}}, \\
& n(\lambda)=A+\frac{B}{\lambda}+\frac{C}{\lambda^{3.5}} \\
& n(\lambda)=A+\frac{B}{(\lambda-C)} .
\end{aligned}
$$

In opposition to the estimation of all optical properties through traditional simulation methods [23, 24], we have developed a new simplified calculation procedure to obtain the wavelength dependencies for the optical properties of a biological material directly from the spectral measurements. This method is simple, and it only needs the adding-doubling simulations to obtain $\mu^{\prime}{ }_{s}$. All the other optical properties are directly calculated from the measured spectra. We have used such method to calculate the wavelength dependencies for all optical properties of human colorectal normal and pathological mucosa between the deep-UV and NIR (200-1000 nm). The calculation method is so sensitive that it allowed us to identify the presence of a pigment that accumulates in different proportions in normal and pathological tissues.

Section 2 explains the experimental and calculation methodology and Section 3 presents the obtained results and corresponding discussion.

\section{Materials and Methods}

\subsection{Tissue Samples}

Following the guidelines of the Ethics Committee of the Portuguese Oncology Institute of Porto, Portugal, colorectal surgical specimens from patients undergoing treatment at that Institution were used to collect the tissue samples for this study. The patients have signed a written consent, allowing the use of surgical resections for diagnostic and research purposes.

Considering the inner layer of the colorectal wall-the mucosa, the normal and pathological areas (see Figure 1) were separated. 


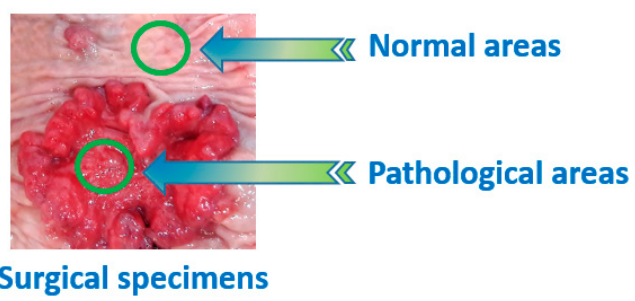

Figure 1. Surgical resection showing both normal and pathological areas of the colorectal mucosa.

A total of 10 samples from the normal and 10 from the pathological areas were prepared to be used in the present study. All the samples were prepared using a cryostat (Leica ${ }^{\mathrm{TM}}$, model CM $1850 \mathrm{UV}$ ) with an approximated circular form, with diameter of about $1 \mathrm{~cm}$ and uniform thickness of $0.5 \mathrm{~mm}$. All these samples were submitted to various spectral measurements, as described in the following sub-section.

\subsection{Spectral Measurements}

The spectral measurements necessary to calculate the optical properties are $T_{\mathrm{t}}, R_{\mathrm{t}}$, and $T_{\mathrm{c}}$. Figure 2 presents a mixed scheme of the measurement setups to obtain these spectra.

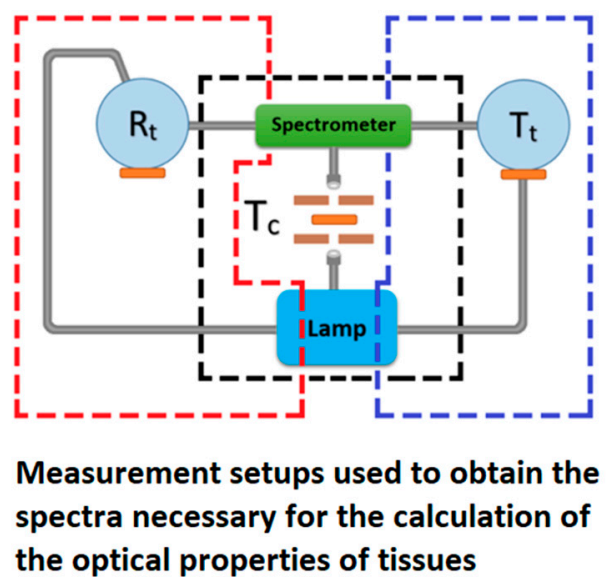

Figure 2. Schematic of the measurement setups to obtain $T_{\mathrm{t}}, R_{\mathrm{t}}$ and $T_{\mathrm{c}}$ spectra.

Considering Figure 2, the setup to measure $R_{\mathrm{t}}$ is presented inside the left-dashed red line, the setup to measure $T_{\mathrm{c}}$ is presented inside the center-dashed black line and the setup to measure $T_{\mathrm{t}}$ is presented inside the right-dashed blue line. For the measurements of $R_{\mathrm{t}}$ and $T_{\mathrm{t}}$, a pulsed high-power and broad-band xenon lamp was used, while to measure $T_{c}$, a deuterium-halogen lamp was used. In all setups, light was delivered and collected with optical fiber cables and collimated lenses. All this equipment was acquired from Avantes ${ }^{\mathrm{TM}}$ (Apeldoorn, The Netherlands). While in the $R_{\mathrm{t}}$ and $T_{\mathrm{t}}$ measurements a $6 \mathrm{~mm}$ beam is used to acquire the spectra through an integrating sphere, in the $T_{\mathrm{C}}$ measurements, a collimated beam of $1 \mathrm{~mm}$ is established by a set of pinholes below and above the sample.

All the 20 samples (10 normal and 10 pathological) were used to perform each of the three measurements, so that average results for the optical properties could be calculated.

\subsection{Calculations}

As indicated in Section 1, with the exception of $\mu^{\prime}{ }_{s}$, our method allows obtaining all other optical properties of a tissue through direct calculation from the spectral measurements. Such a method is fast, simple, and straightforward, as represented schematically in Figure 3 and described below. 


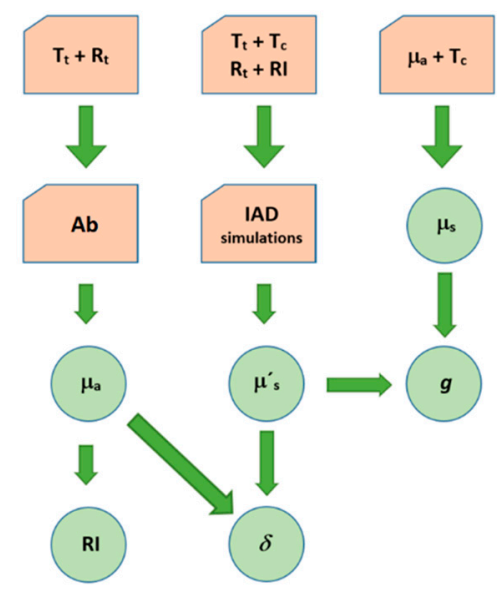

Figure 3. Calculation procedure to obtain the optical properties of a tissue from spectral measurements.

The first calculation step consists on obtaining the wavelength dependence for the absorbance $(A b)$ of the tissue sample. Such a calculation is made with Equation (9), using the $R_{\mathrm{t}}$ and $T_{\mathrm{t}}$ spectra.

$$
A b(\lambda)=1-\left(\frac{T_{t}(\lambda)+R_{t}(\lambda)}{100}\right) .
$$

By dividing $A b(\lambda)$ by the sample thickness, we obtain $\mu_{\mathrm{a}}(\lambda)$, which can be used to calculate the real part of the RI of the tissue, $n_{\text {tissue }}(\lambda)$.

In this calculation, to obtain the tissue's dispersion, we start by obtaining the imaginary part of tissue's RI, $k(\lambda)$, through Equation 10 [30]:

$$
\kappa(\lambda)=\frac{\lambda}{4 \pi} \mu_{a}(\lambda)
$$

With this calculation, $\kappa(\lambda)$ can be used in the following Kramers-Kronig $(\mathrm{K}-\mathrm{K})$ relation to obtain $n_{\text {tissue }}(\lambda)[30,31]:$

$$
n_{\text {tissue }}(\lambda)=1+\frac{2}{\pi} \int_{0}^{\infty} \frac{\lambda}{\Lambda} \times \frac{\lambda}{\Lambda^{2}-\lambda^{2}} \kappa(\lambda) \mathrm{d} \Lambda,
$$

where $\Lambda$ represents the integrating variable over a wavelength range under consideration and $\lambda$ is a fixed wavelength in that range that can be tuned for better adjustment of the calculated dispersion. Such better adjustment is obtained if some experimental RI data for some wavelengths and/or a possible dispersion curve for the tissue in a smaller spectral range than the one to be considered are available [32].

The following step consists of obtaining the $\mu^{\prime}{ }_{s}$ data through inverse adding-doubling (IAD) simulations [23]. To perform these simulations, sample thickness, $T_{t}, R_{t}, T_{c}$, and RI data within the wavelength range to consider are used as input. The IAD code used in these estimations is the one developed by Scott Prahl and it is available online at http://omlc.org/software/iad. Such code also generates $\mu_{\mathrm{a}}$, but since we have already calculated it from the $T_{\mathrm{t}}, R_{\mathrm{t}}$ spectra and since each simulation corresponds to a single wavelength, we only collect the $\mu^{\prime}$ s data from the simulations for later reconstruction of its wavelength dependence. The selection of wavelengths to perform these simulations is kept to a minimum since the general curve that describes $\mu^{\prime}{ }_{s}(\lambda)$ is described by Equation (3). In the present study, we considered wavelengths at each $50 \mathrm{~nm}$ between 200 and $1000 \mathrm{~nm}$. Once all the $\mu^{\prime}{ }_{s}$ values for the selected wavelengths are estimated, the data is fitted with Equation (3), and $\mathrm{a}^{\prime}, f_{\text {Ray }}$, and $b_{\text {Mie }}$ are obtained during the fitting.

Using the calculated $\mu_{\mathrm{a}}(\lambda)$ and the estimated $\mu_{\mathrm{s}}{ }_{\mathrm{s}}(\lambda)$ in Equation (2), the wavelength dependence for $\delta, \delta(\lambda)$, is calculated. 
To calculate $\mu_{s}(\lambda)$, the sample thickness, $d, \mu_{a}(\lambda)$, and the $T_{c}$ spectrum are used in Bouguer-Beer-Lambert law [2,10],

$$
\mu_{s}(\lambda)=-\frac{\ln \left[T_{c}(\lambda)\right]}{d}-\mu_{a}(\lambda)
$$

where $\mu_{\mathrm{a}}(\lambda)$ is the one obtained from $T_{\mathrm{t}}$ and $R_{\mathrm{t}}$ spectra through Equation (9).

Finally, $g(\lambda)$ is calculated from $\mu_{s}(\lambda)$ and $\mu_{s}^{\prime}(\lambda)$ through Equation (1).

The calculation procedure here described was used to obtain the mean optical properties for human colorectal mucosa (normal and pathological) tissues. By analyzing such calculated properties, it was possible to identify some spectral signatures and also to detect different pigment accumulation in normal and pathological mucosa. Such distinct accumulation of this pigment can be used in future for the development of a noninvasive diagnostic method, based on diffuse reflectance, $R_{\mathrm{d}}$, measurements. Section 3 presents the results of this study and corresponding discussion.

\section{Results}

We initiated the present study by performing the spectral measurements from the normal and pathological tissue samples. Figure 4 presents the mean of $10 T_{\mathrm{t}}$ spectra and standard deviation (SD) bars for normal and pathological mucosa.

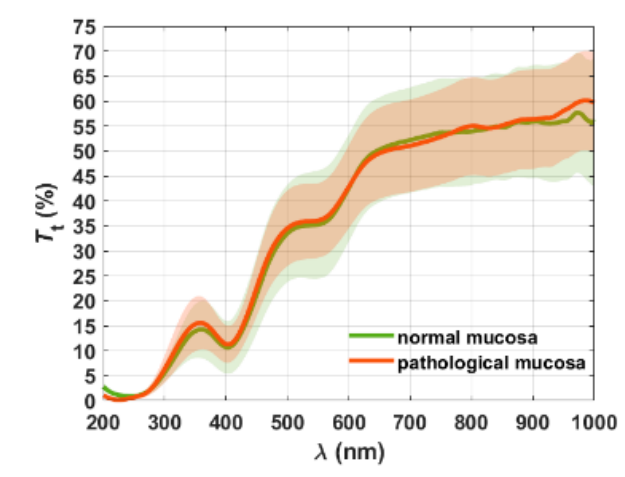

Figure 4. Mean $T_{\mathrm{t}}$ spectra of the normal and pathological mucosa.

We see from the mean spectra in Figure 4 that both tissues present low transmittance in the deep-UV range. The form and magnitude of the $T_{\mathrm{t}}$ spectra is similar for both tissues, showing an increasing behavior with increasing wavelength and the absorption bands of hemoglobin near $415 \mathrm{~nm}$ (Soret-oxygenated hemoglobin) and $550 \mathrm{~nm}$ (deoxygenated hemoglobin) [33].

Figure 5 presents the mean of $10 R_{\mathrm{t}}$ spectra and SD bars for normal and pathological mucosa.

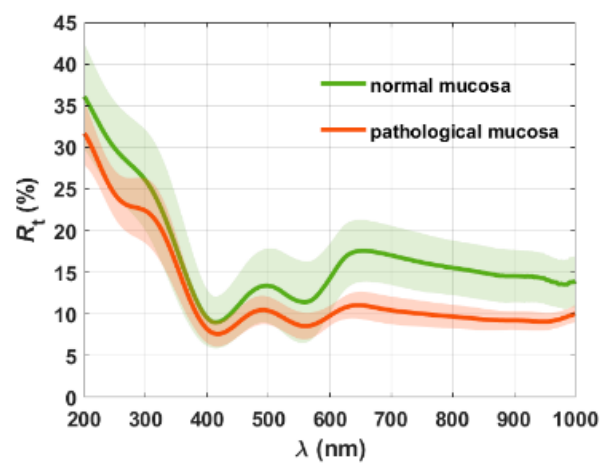

Figure 5. Mean $R_{\mathrm{t}}$ spectra of the normal and pathological mucosa. 
Comparing between the spectra in graphs of Figure 5 we see that both tissues show similar magnitude and wavelength dependence for $R_{\mathrm{t}}$. Once again, the occurrence of two absorption bands near 415 and $550 \mathrm{~nm}$ indicate the presence of both oxygenated and deoxygenated hemoglobin [33].

Figure 6 presents the mean of $10 T_{\mathrm{c}}$ spectra and SD bars for normal and pathological mucosa.

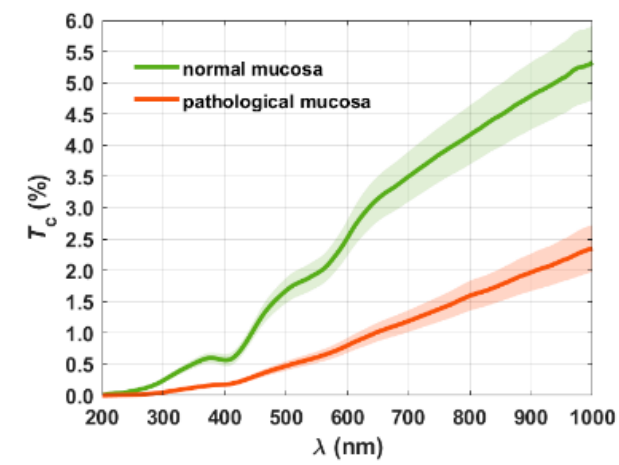

Figure 6. Mean $T_{\mathrm{c}}$ spectra of the normal and pathological mucosa.

Considering the sensitive $T_{\mathrm{c}}$ measurements presented in Figure 6 , we see that, although the wavelength dependence is similar for both tissues, some differences are visible. The normal mucosa seems to have higher blood content, since the magnitude of the absorption bands of hemoglobin is higher than in the pathological mucosa. On the other hand, the $T_{\mathrm{c}}$ magnitude is higher for the normal mucosa in the entire spectral range, a fact that may mislead in the evaluation of the total blood content in both tissues.

Using the individual $T_{\mathrm{t}}$ and $R_{\mathrm{t}}$ spectra that originated the mean curves in graphs of Figures 4 and 5 in Equation (9), we calculated 10 absorption spectra, $A b(\lambda)$, for each tissue, which were then divided by the sample thickness, $d=0.05 \mathrm{~cm}$, to obtain the $10 \mu_{\mathrm{a}}(\lambda)$ curves. Figure 7 presents the mean $\mu_{\mathrm{a}}(\lambda)$ curves and corresponding SD bars for both tissues.

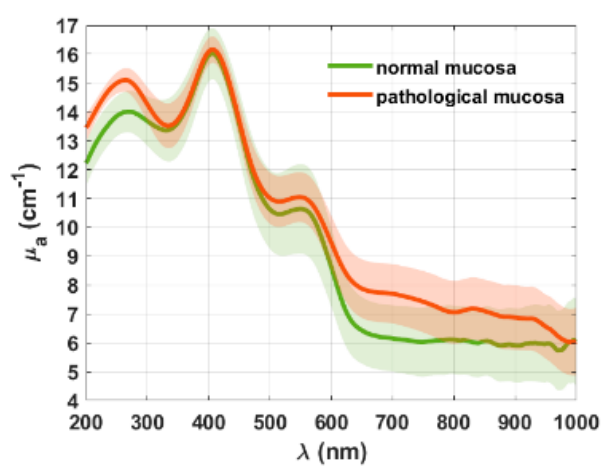

Figure 7. Mean $\mu_{\mathrm{a}}(\lambda)$ of the normal and pathological mucosa.

Both datasets in Figure 7 show that these tissues present a typical wavelength dependence for $\mu_{a}$, since its magnitude decreases with increasing wavelength from the UV to the NIR wavelengths. These spectra show three absorption bands: the first one at $268 \mathrm{~nm}$, which is a combination of the absorption bands of DNA (260 nm) and hemoglobin $(274 \mathrm{~nm})$, the second at $415 \mathrm{~nm}$ (Soret band), and the third near $550 \mathrm{~nm}$ (deoxygenated hemoglobin) [33].

The mean curves in Figure 7 were used in calculations with Equations(10) and (11) to obtain tissue's dispersions. The solid lines in Figure 8 present the result of this calculation for both tissues, along with the previously estimated Cornu curves (dashed lines) [34], now extended to $200 \mathrm{~nm}$ for comparison. 


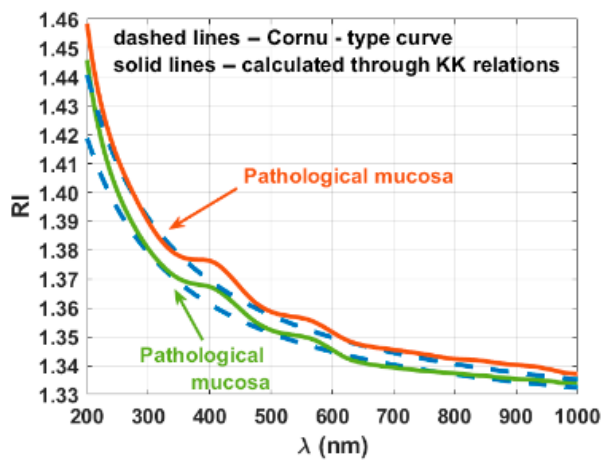

Figure 8. Tissue dispersion calculated through K-K relations and by Cornu-fitting of experimental data for the normal and pathological mucosa.

Considering the datasets for each tissue in Figure 8, the dispersion obtained from the absorption spectrum (solid line) and the one calculated from experimental RI data (dashed line) [34] show good agreement.

After calculating the dispersions of both tissues between 200 and $1000 \mathrm{~nm}$, we had all the necessary data to perform the IAD simulations. Those simulations were performed for both tissues, using the sample thickness of $0.05 \mathrm{~cm}$, and the spectral data from mean $T_{\mathrm{t}}$, mean $R_{\mathrm{t}}$, mean $T_{\mathrm{c}}$ and the calculated dispersions, as presented in graphs of Figures 4-6 and Figure 8. The estimated $\mu^{\prime}$ s values and the fitting curves described by Equation (3) are presented in Figure 9.

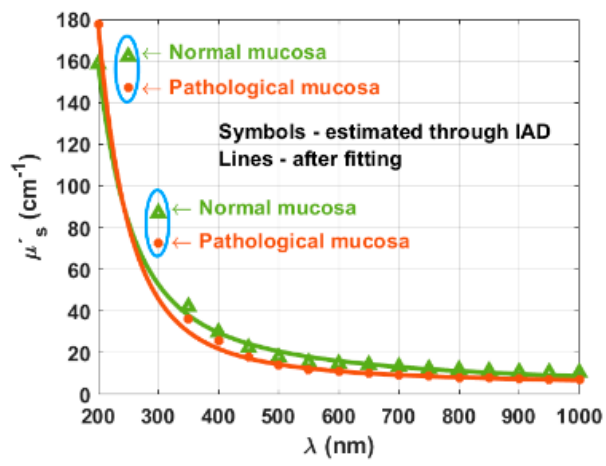

Figure 9. Estimated $\mu^{\prime}$ s data and calculated fitting curve for the normal and pathological mucosa.

As we can see from curves in Figure 9, to obtain a good fitting (R-square $>0.997$ in both cases), we needed to neglect some of the estimated points (points inside blue lines). The estimated curves show the smooth-decreasing behavior with increasing wavelength, indicating that both tissues have strong and multiple scattering at short-wavelengths. Since the simulations that generated the $\mu_{s}^{\prime}$ points presented in Figure 9 were made using the mean experimental spectra, no SD bars are presented. Comparing both tissues, we see that the magnitude of $\mu^{\prime}{ }_{s}$ in the pathological mucosa is lower for wavelengths in the NIR range and higher in the deep-UV region, near $200 \mathrm{~nm}$, which suggests a higher protein content in this tissue as reported by Peña-Llopis and Brugarolas [35].

When performing the fitting of the estimated $\mu^{\prime}{ }_{s}$ data, we obtained the following equations for the curves presented in Figure 9.

$$
\begin{aligned}
\mu^{\prime}{ }_{\text {s-normal }}(\lambda) & =20.76 \times\left(0.137 \times\left(\frac{\lambda}{500(\mathrm{~nm})}\right)^{-4}+(1-0.137) \times\left(\frac{\lambda}{500(\mathrm{~nm})}\right)^{-1.068}\right), \\
\mu^{\prime}{ }_{\text {s-pathological }}(\lambda) & =14.47 \times\left(0.2806 \times\left(\frac{\lambda}{500(\mathrm{~nm})}\right)^{-4}+(1-0.2806) \times\left(\frac{\lambda}{500(\mathrm{~nm})}\right)^{-0.6621}\right),
\end{aligned}
$$


The following step consisted on obtaining $\mu_{\mathrm{s}}(\lambda)$ for both tissues. Considering the $10 T_{\mathrm{c}}$ spectra measured from a particular tissue and the calculated $\mu_{\mathrm{a}}(\lambda)$ curves, $10 \mu_{\mathrm{s}}(\lambda)$ curves were calculated with Equation (12). Figure 10 presents the calculated mean $\mu_{s}(\lambda)$, after adjusting with a curve as described by Equation (3), and SD bars for both tissues.

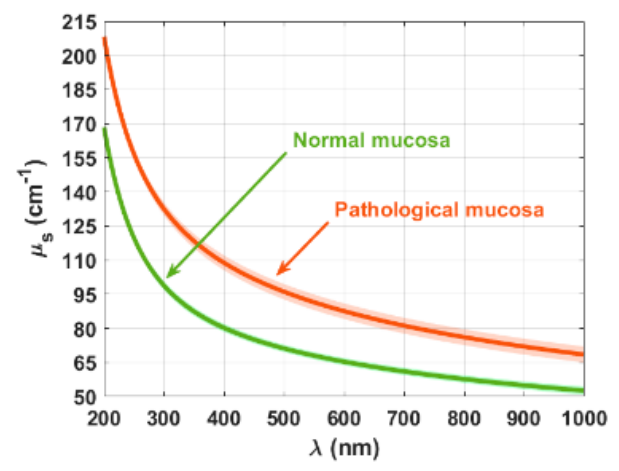

Figure 10. Calculated $\mu_{\mathrm{s}}(\lambda)$ curves for the normal and pathological mucosa.

Both curves in Figure 10 show the expected smooth-decreasing behavior, and low SD values along the entire spectral range, meaning that scattering is not too different from one sample to another within the sample groups of normal and pathological mucosa used in the present study. Similar to what was observed for $\mu_{s}^{\prime}$, the pathological mucosa presents higher magnitude values for $\mu_{s}$ in the deep-UV, indicating a higher protein content. The curves presented in Figure 10 are described by the following equations, which were obtained with R-square values of 0.9978 (normal mucosa) and 0.9989 (pathological mucosa).

$$
\begin{gathered}
\mu_{\text {s-normal }}(\lambda)=71.14 \times\left(0.0244 \times\left(\frac{\lambda}{500(\mathrm{~nm})}\right)^{-4}+(1-0.0244) \times\left(\frac{\lambda}{500(\mathrm{~nm})}\right)^{-0.4035}\right) \\
\mu_{\text {s-pathological }}(\lambda)=96.07 \times\left(0.0169 \times\left(\frac{\lambda}{500(\mathrm{~nm})}\right)^{-4}+(1-0.0169) \times\left(\frac{\lambda}{500(\mathrm{~nm})}\right)^{-0.4665}\right)
\end{gathered}
$$

After obtaining the curves for $\mu^{\prime}{ }_{s}(\lambda)$ and $\mu_{s}(\lambda)$ for both tissues, we used Equation (1) to calculate $g(\lambda)$. Figure 11 presents the results of these calculations.

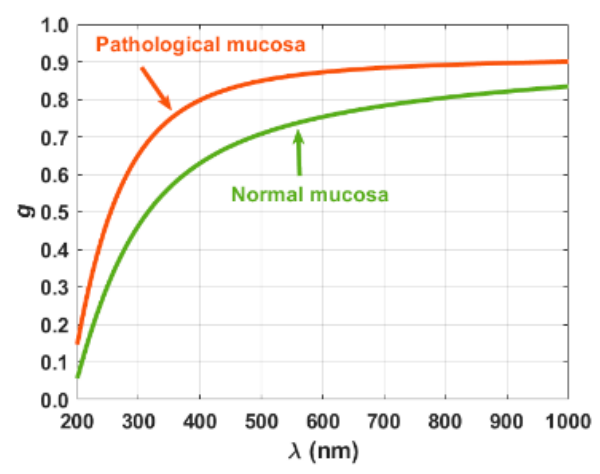

Figure 11. Calculated $g(\lambda)$ curves for the normal and pathological mucosa.

Figure 11 shows that both tissues present a good wavelength dependence for $g$ in the entire spectral range $-g$ increases with wavelength from the deep-UV to NIR. The pathological mucosa presents higher $g$ values than the normal mucosa in the entire spectral range, which suggests a higher scattering directionality at all wavelengths. Considering the range between 200 and $230 \mathrm{~nm}$, such higher 
scattering directionality might be due to the presence of a higher protein content in the pathological mucosa. For the longer wavelengths, higher-sized structures that emerge during cancer development might be responsible for the higher scattering directionality.

To obtain the equations that describe the curves presented in Figure 11, we used the curve fitting tool of MATLAB ${ }^{\mathrm{TM}}$ to fit that data.

$$
\begin{aligned}
& g(\lambda)=0.6763 \cdot \exp \left(2.171 \times 10^{-4} \cdot \lambda\right)-3.946 \cdot \exp \left(-9.055 \times 10^{-3} \cdot \lambda\right) \\
& g(\lambda)=0.8335 \cdot \exp \left(8.226 \times 10^{-5} \cdot \lambda\right)-8.028 \cdot \exp \left(-12.25 \times 10^{-3} \cdot \lambda\right) .
\end{aligned}
$$

These fittings were obtained with R-square values of 0.9998 for the normal mucosa and 0.9997 for the pathological mucosa. Finally, using $\mu_{\mathrm{a}}(\lambda)$ and $\mu^{\prime}{ }_{s}(\lambda)$ in Equation (2), we calculated $\delta(\lambda)$ for both tissues. The results of these calculations are presented in Figure 12.

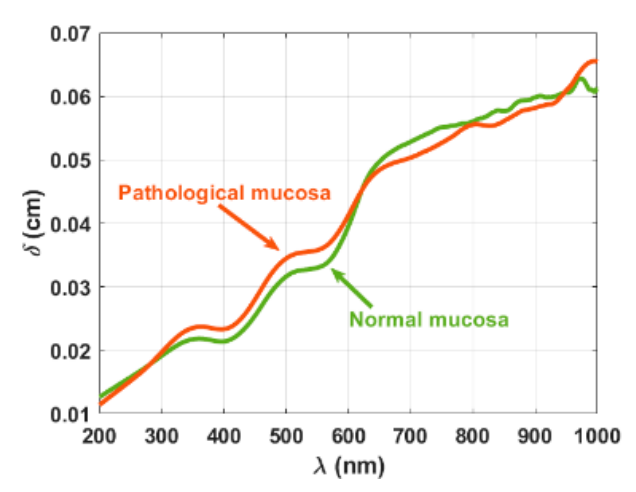

Figure 12. Calculated $\delta(\lambda)$ curves for the normal and pathological mucosa.

Both curves in Figure 12 show the expected wavelength dependence for $\delta$. These curves also show the absorption bands of hemoglobin near 415 and $550 \mathrm{~nm}$. For the case of the pathological mucosa, the occurrence of a double absorption band with peaks near 830 and $930 \mathrm{~nm}$ indicates that some lipids have accumulated in this tissue during cancer development as reported [34]. Comparing the magnitude of the $\delta$ values in curves of Figure 12 with others previously reported for other mucosal tissues, such as mucous membrane from the human maxillary sinus [36], we see that our results are approximately $10 \times$ less. Wondering why such difference occurs between our calculated and other published data for mucous tissues, we supposed that some pigment has accumulated in the mucosal tissues used in our study, leading to a reduced light penetration depth through increased absorption in the entire spectral range. Other tissue fragments that were retrieved from the same surgical specimens were analyzed at the Portuguese Oncology Institute of Porto, and consulting the clinical records of those tissues, we found some information that is vital to interpret our results. According to these records, as a result of a natural product that was administered to the patients in the two days before the surgical procedure, a lipofuscin-type pigment has accumulated in the colorectal mucosa. Lipofuscin presents a wavelength dependence that decreases in an exponential manner with increasing wavelength $[37,38]$.

Trying to acquire additional information about this pigment that has accumulated in both tissues, we returned to the $\mu_{\mathrm{a}}$ data presented in Figure 7. Considering the absorption peaks of hemoglobin in the visible range, we calculated the ratios between the $\mu_{\mathrm{a}}$ values at those peaks and the ones from the baseline and found that both normal and pathological tissues present a 2.7-fold ratio at 415 and a 1.8-fold ratio at $550 \mathrm{~nm}$. According to Bashkatov et al. [36], these ratios should be higher for the normal mucosa. On the other hand, they should also be different between normal and pathological mucosa due to a higher blood content in cancer tissues, as previously reported [17]. By obtaining such equal ratios at 415 and $550 \mathrm{~nm}$ for normal and pathological tissues, we get a confirmation that some absorber is hiding the true blood content in the mucosa tissues used in our study. To obtain the wavelength dependence for the $\mu_{\mathrm{a}}$ of such pigment, we tried some curves that have an exponential decreasing 
behavior with increasing wavelength, similar to lipofuscin [37,38]. During these trials, we found that a curve described by Equation (19) can be subtracted to the $\mu_{\mathrm{a}}(\lambda)$ of the normal mucosa to produce acceptable ratios at $415 \mathrm{~nm}$ (19.7-fold) and at $550 \mathrm{~nm}$ (10.1-fold), which resemble the ratios reported for other mucosal tissues [36].

$$
\mu_{\text {a-pigment }}(\lambda)=A \times e^{(3.524-0.0187 . \lambda)}
$$

In this equation, $\mu_{\text {a-pigment }}$ is represented in $\mathrm{cm}^{-1}$ and $\lambda$ in $\mathrm{nm} . A$ represents the percentage content of the pigment in the tissue, which in the case of normal mucosa assumes the value $1(100 \%)$. Equation (19) has the same mathematical form as the one reported for lipofuscin in cerebral tissues [38], but its numerical factors needed to be adjusted to fit the wavelength dependence of the lipofuscin-type pigment in colorectal tissues. The similar curve was also subtracted to the $\mu_{\mathrm{a}}$ graph of the pathological mucosa, but to obtain reasonable blood content in that tissue, we had to consider $A=1.1$ in Equation (19), a $10 \%$ higher content of the pigment in the pathological tissue. Figure 13 presents the $\mu_{\mathrm{a}}$ graphs for normal and pathological tissues, before and after subtracting the absorption of the pigment. The absorption of the pigment, as described by Equation (19), is also represented in graphs of Figure 13, considering $100 \%$ content in the normal and $110 \%$ in the pathological mucosa.

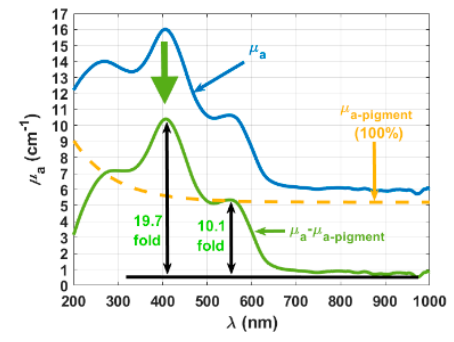

(a)

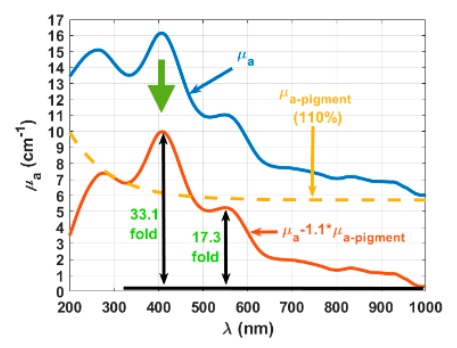

(b)

Figure 13. Wavelength dependencies of $\mu_{\mathrm{a}}$ for the pigment, for normal (a) and for pathological (b) mucosa, before and after subtracting the absorption of the pigment.

The results presented in the graphs of Figure 13 present two important results. The first one is that the lipofuscin-type pigment accumulates differently in the normal and pathological mucosa, since to obtain these results, we had to consider a $10 \%$ higher content of the pigment in the pathological tissue. The second result is that by subtracting the absorption of the pigment in the two tissues, the pathological mucosa presents higher blood content than the normal mucosa, as previously reported [17].

\section{Conclusions}

The present study consisted on calculating the wavelength dependencies for the optical properties of biological tissues, directly from spectral measurements. With the exception of $\mu^{\prime}$, which needs to be estimated through IAD simulations, the method here introduced allows a fast evaluation of the basic optical properties of any biological tissue as a function of wavelength, provided that $T_{\mathrm{t}}, R_{\mathrm{t}}$ and $T_{\mathrm{C}}$ spectra are collected. Such method is sensitive enough to detect spectral signatures in the calculated optical properties and to allow differentiation between normal and pathological tissues.

By using spectral measurements from human colorectal tissues, it was possible to verify that the proposed calculation method produces the expected wavelength dependencies for all optical properties. The use of K-K relations to obtain the real part of the RI of tissues has also been demonstrated effective and reliable, since the calculated dispersions match almost perfectly the previous calculated curves that fit experimental RI data between 400 and $1000 \mathrm{~nm}$. Since the dispersions calculated through K-K relations are obtained from the spectral measurements, they also show spectral signatures, which were not obtained when fitting the experimental RI data. By comparing the magnitude of the calculated penetration depth values with previously reported data for other mucosal tissues, it was possible to identify the presence of an additional absorber both in normal and pathological mucosa tissues and to 
quantify a higher content in the pathological tissue. Such information may be used in the future in the development of noninvasive spectroscopic diagnostic procedures, based on $R_{\mathrm{d}}$ spectral measurements. It will be interesting to use this same methodology for the evaluation of the optical properties of other tissues, both in normal or pathological samples to obtain discriminating information that can be useful for the diagnostic of different diseases or other types of cancer.

Author Contributions: Conceptualization, V.T. and L.O.; methodology, V.T. and L.O.; investigation, S.C., I.C., R.H., and L.O.; writing - original draft preparation, S.C., I.C., and L.O.; writing-review and editing, R.H. and V.T.; project administration, V.T. and L.O. All authors have read and agreed to the published version of the manuscript.

Funding: This research was funded by the Portuguese Science Foundation, grant number FCT-UIDB/04730/2020 and VVT was funded by RFBR grant 18-29-02060 MK.

Conflicts of Interest: The authors declare no conflict of interest.

\section{References}

1. Brenner, H.; Kloor, M.; Pox, C.P. Colorectal cancer. Lancet 2014, 383, 1490-1502. [CrossRef]

2. Oliveira, L.M.; Tuchin, V.V. The Optical Clearing Method-A New Tool for Clinical Practice and Biomedical Engineering; SPRINGER: Cham, Switzerland, 2019; pp. 1-106.

3. Sordillo, D.C.; Sordillo, L.A.; Sordillo, P.P.; Shi, L.; Alfano, R.R. Short wavelength infrared optical windows for evaluation of benign and malignant tissues. J. Biomed. Opt. 2017, 22. [CrossRef]

4. Shi, L.; Sordillo, L.A.; Rodríguez-Contreras, A.; Alfano, R. Transmission in near-infrared optical windows for deep brain imaging. J. Biophotonics 2016, 9, 38-43. [CrossRef] [PubMed]

5. Bashkatov, A.N.; Genina, E.A.; Kozintseva, M.D.; Kochubei, V.I.; Gorodkov, S.Y.; Tuchin, V.V. Optical properties of peritoneal biological tissues in the spectral range of 350-2500 nm. Opt. Spectrosc. 2016, 120, 6-14. [CrossRef]

6. Carneiro, I.; Carvalho, S.; Henrique, R.; Oliveira, L.; Tuchin, V. Moving tissue spectral window to the deep-ultraviolet via optical clearing. J. Biophotonics 2019, 12. [CrossRef] [PubMed]

7. Carneiro, I.; Carvalho, S.; Henrique, R.; Selifonov, S.; Oliveira, L.; Tuchin, V.V. Enhanced ultraviolet spectroscopy by optical clearing for biomedical applications. IEEE J. Sel. Top. Quant. Elect. 2021, 27. [CrossRef]

8. Oliveira, L.M.; Zaytsev, K.I.; Tuchin, V.V. Improved biomedical imaging over a wide spectral range from UV to THz towards multimodality. In SPIE Proceedings of the Third International Conference on Biophotonics Riga 2020, Riga, Latvia, 24-25 August 2020; Spigulis, J., Ed.; SPIE: Bellingham, WA, USA, 2020; Volume 11585, p. 11585.

9. Bashkatov, A.N.; Genina, E.A.; Kochubey, V.I.; Rubtsov, V.S.; Kolesnikova, E.A.; Tuchin, V.V. Optical properties of human colon tissues in the 350-2500 spectral range. Quant. Elect. 2014, 44, 779-784. [CrossRef]

10. Tuchin, V.V. Tissue Optics: Light Scattering Methods and Instruments for Medical Diagnosis, 3rd ed.; SPIE Press: Bellingham, WA, USA, 2015; pp. 245-358.

11. Vo-Dinh, T. Biomedical Photonics Handbook, 2nd ed.; CRC Press: Boca Raton, FL, USA, 2014; Volume 1, pp. 23-168.

12. Bashkatov, A.N.; Genina, E.A.; Kochubey, V.I.; Tuchin, V.V. Optical properties of human skin, subcutaneous and mucous tissues in the wavelength range from 400 to $2000 \mathrm{~nm}$. J. Phys. D Appl. Phys. 2005, 38, 2543. [CrossRef]

13. Bashkatov, A.N.; Genina, E.A.; Kochubey, V.I.; Tuchin, V.V. Optical properties of the subcutaneous adipose tissue in the spectral range 400-2500 nm. Opt. Spectrosc. 2005, 99, 836-842. [CrossRef]

14. Bashkatov, A.N.; Genina, E.A.; Kochubey, V.I.; Tuchin, V.V. Optical properties of human cranial bone in the spectral range from 800 to $2000 \mathrm{~nm}$. In SPIE Proceedings of the Saratov Fall Meeting 2005: Optical Technologies in Biophysics and Medicine VII, Saratov, Russian, 27-30 September 2005; Tuchin, V.V., Ed.; SPIE: Bellingham, WA, USA, 2006; Volume 6163, p. 6163.

15. Bashkatov, A.N.; Genina, E.A.; Kochubey, V.I.; Gavrilova, A.A.; Kapralov, S.V.; Grishaev, V.A.; Tuchin, V.V. Optical properties of human stomach mucosa in the spectral range from 400 to $2000 \mathrm{~nm}$ : Prognosis for gastroenterology. Med. Las. Appl. 2007, 22, 95-104. [CrossRef]

16. Bashkatov, A.N.; Genina, E.A.; Kochubey, V.I.; Tuchin, V.V. Optical properties of human sclera in spectral range 370-2500 nm. Opt. Spectrosc. 2010, 109, 197-204. [CrossRef] 
17. Carvalho, S.; Gueiral, N.; Nogueira, E.; Henrique, R.; Oliveira, L.; Tuchin, V. Comparative study of the optical properties of colon mucosa and colon precancerous polyps between 400 and $1000 \mathrm{~nm}$. In SPIE Proceedings of BIOS-Photonics West 2017: Dynamics and Fluctuations in Biomedical Photonics, San Francisco, CA, USA, 28 January-2 February 2017; Tuchin, V.V., Larin, K.V., Leahy, M.J., Wang, R.K., Eds.; SPIE: Bellingham, WA, USA, 2017; Volume 10063, p. 10063.

18. Carneiro, I.; Carvalho, S.; Henrique, R.; Oliveira, L.; Tuchin, V.V. Optical properties of colorectal muscle in visible/NIR range. In SPIE Proceedings of Photonics Europe: Biophotonics_Photonic Solutions for Better Health Care VI, Strasbourg, France, 22-26 April 2018; Popp, J., Tuchin, V.V., Pavone, F.S., Eds.; SPIE: Bellingham, WA, USA, 2018; Volume 10685, p. 10685.

19. Carneiro, I.; Carvalho, S.; Henrique, R.; Oliveira, L.; Tuchin, V.V. Measuring optical properties of human liver between 400 and $1000 \mathrm{~nm}$. Quant. Electr. 2019, 49, 13-19. [CrossRef]

20. Jacques, S.L. Optical properties of biological tissues: A review. Phys. Med. Biol. 2013, 58, R37-R61. [CrossRef] [PubMed]

21. Carneiro, I.; Carvalho, S.; Silva, V.; Henrique, R.; Oliveira, L.; Tuchin, V.V. Kinetics of optical properties of human colorectal tissues during optical clearing: A comparative study between normal and pathological tissues. J. Biomed. Opt. 2018, 23. [CrossRef]

22. Carneiro, I.; Carvalho, S.; Henrique, R.; Oliveira, L.; Tuchin, V.V. Kinetics of Optical Properties of Colorectal Muscle During Optical Clearing. IEEE J. Sel. Top. Quant. Elect. 2019, 25. [CrossRef]

23. Prahl, S.A.; van Gemert, M.J.C.; Welch, A.J. Determining the optical properties of turbid media by using the adding-doubling method. Appl. Opt. 1993, 32, 559-568. [CrossRef] [PubMed]

24. Wang, L.; Jacques, S.L.; Zheng, L. MCML-Monte Carlo modeling of light transport in multi-layered tissues. Comp. Method Prog. Biomed. 1995, 47, 131-146. [CrossRef]

25. Ianina, I.Y.; Lazareva, E.N.; Tuchin, V.V. Refractive index of adipose tissue and lipid droplet measured in wide spectral and temperature ranges. Appl. Opt. 2018, 57, 4839-4848. [CrossRef]

26. Lazareva, E.N.; Tuchin, V.V. Measurement of refractive index of hemoglobin in the visible/NIR spectral range. J. Biomed. Opt. 2018, 23. [CrossRef]

27. Lazareva, E.N.; Tuchin, V.V. Blood refractive index modelling in the visible and near infrared spectral regions. J. Biomed. Photonics Eng. 2018, 4. [CrossRef]

28. Carneiro, I.; Carvalho, S.; Henrique, R.; Oliveira, L.; Tuchin, V.V. Water content and scatterers dispersion evaluation in colorectal tissues. J. Biomed. Photonics Eng. 2017, 3, 40301. [CrossRef]

29. Carneiro, I.; Carvalho, S.; Henrique, R.; Oliveira, L.; Tuchin, V.V. Simple multimodal technique for evaluation of free/bound water and dispersion of human liver tissue. J. Biomed. Opt. 2017, 22. [CrossRef]

30. Sydoruk, O.; Zhernovaya, O.; Tuchin, V.V.; Douplik, A. Refractive index of solutions of human hemoglobin from the near-infrared to the ultraviolet range: Kramers-Kronig analysis. J. Biomed. Opt. 2012, 17. [CrossRef] [PubMed]

31. Gienger, J.; Gro $\beta$, H.; Neukammer, J.; Bär, M. Determining the refractive index of human hemoglobin solutions by Kramers-Kronig relations with an improved absorption model. Appl. Opt. 2016, 55, 8951-8961. [CrossRef] [PubMed]

32. Gomes, N.; Tuchin, V.V.; Oliveira, L.M. UV-NIR efficiency of the refractive index matching mechanism on colorectal muscle during treatment with different glycerol osmolarities. J. Biomed. Photonics Eng. 2020, 6, 20307. [CrossRef]

33. Zhou, Y.; Yao, J.; Wang, L. Tutorial on photoacoustic tomography. J. Biomed. Opt. 2006, 6, 61007. [CrossRef]

34. Carvalho, S.; Gueiral, N.; Nogueira, E.; Henrique, R.; Oliveira, L.; Tuchin, V.V. Wavelength dependence of the refractive index of human colorectal tissues: Comparison between healthy mucosa and cancer. J. Biomed. Photonics Eng. 2016, 2. [CrossRef]

35. Peña-Llopis, S.; Brugarolas, J. Simultaneous isolation of high-quality DNA, RNA, miRNA and proteins from tissues for genomic applications. Nat. Protoc. 2017, 8, 2240-2255. [CrossRef]

36. Bashkatov, A.N.; Genina, E.A.; Kochubey, V.I.; Tuchin, V.V.; Chikina, E.E.; Knyazev, A.B.; Mareev, O.V. Optical properties of mucous membrane in the spectral range 350-2000 nm. Opt. Spect. 2004, 97, 1043-1048. [CrossRef] 
37. Johansson, J.D. Spectroscopic method for determination of the absorption coefficient in brain tissue. J. Biomed. Opt. 2010, 15. [CrossRef]

38. Johansson, J.D.; Wårdell, K. Intracerebral quantitative chromophore estimation from reflectance spectra captured during deep brain stimulation implantation. J. Biophotonics 2013, 6, 435-445. [CrossRef] [PubMed]

Publisher's Note: MDPI stays neutral with regard to jurisdictional claims in published maps and institutional affiliations.

(C) 2020 by the authors. Licensee MDPI, Basel, Switzerland. This article is an open access article distributed under the terms and conditions of the Creative Commons Attribution (CC BY) license (http://creativecommons.org/licenses/by/4.0/). 